\title{
Early occurrence of lung adenocarcinoma and breast cancer after radiotherapy of a chest wall sarcoma in a patient with a de novo germline mutation in TP53
}

\author{
Alessandra Ferrarini • Agnes Auteri-Kaczmarek • Alessia Pica • \\ Nemya Boesch • Karl Heinimann - Stephan C. Schäfer • Sara Vesnaver-Megalo • \\ Viviane Cina $\cdot$ Jacques S. Beckmann $\cdot$ Christian Monnerat
}

Published online: 12 January 2011

(C) Springer Science+Business Media B.V. 2011

\begin{abstract}
We report a 26-year-old female patient who was diagnosed within 4 years with chest sarcoma, lung adenocarcinoma, and breast cancer. While her family history was unremarkable, DNA sequencing of TP53 revealed a germline de novo non-sense mutation in exon 6 p.Arg213X. One year later, she further developed a contralateral ductal carcinoma in situ, and 18 months later a jaw osteosarcoma. This case illustrates the therapeutic pitfalls in the care of a young cancer patient with TP53 de novo germline mutations and the complications related to her first-line therapy. Suggestion is made to use the less stringent Chompret criteria for germline TP53 mutation screening. Our observation underlines the possibly negative effect of radiotherapy in generating second tumors in patients with a TP53 mutation. We also present a review of six previously reported cases, comparing their cancer phenotypes with those generally produced by TP53 mutations.
\end{abstract}

A. Ferrarini $\cdot$ S. Vesnaver-Megalo $\cdot$ V. Cina $\cdot$

J. S. Beckmann · C. Monnerat ( $\square)$

Service de Génétique Médicale, CHUV, Lausanne, Switzerland

e-mail: christian.monnerat@ne.ch

A. Auteri-Kaczmarek

Fondation du Centre pluridisciplinaire d'Oncologie, CHUV,

Lausanne, Switzerland

A. Pica

Service de Radio-Oncologie, CHUV, Lausanne, Switzerland

N. Boesch · K. Heinimann

Department of biomedicine, Division of Medical Genetics,

University Children's Hospital, Basel, Switzerland

S. C. Schäfer

Service de Pathologie, CHUV, Lausanne, Switzerland
Keywords Li-Fraumeni syndrome $\cdot$ Germline mutation TP53 · De novo mutation · p.Arg213X

\section{Introduction}

Li-Fraumeni syndrome (LFS) is one of the most severe forms of familial cancer susceptibility syndrome, characterized by an early age of tumor onset and a wide tumor spectrum. According to its first description [1], diagnosis should be suspected in the presence of a bone or soft tissue sarcoma in a patient under 45 years of age and a family history with a first-degree relative with any cancer under 45 years, or a sarcoma at any age. However, LFS is rarely diagnosed in routine clinical practice, and the French LFS working group has elaborated practical criteria (Chompret criteria, Table 1), which were recently updated [2]. These criteria are less stringent than the original LFS criteria [1] and have a higher sensitivity that could allow more cases to be detected.

No other genes than TP53 have been convincingly associated with LFS [3]. Using current techniques (sequence analysis, deletion testing), TP53 mutation is detected in about $70 \%$ of LFS families [4]. Molecular diagnosis of these cases is critically important to ensure an appropriate medical follow-up and to avoid inappropriate cancer treatment such as radiation therapy. De novo mutations of TP53 represent a clinical pitfall, since the mutational status is not suspected at the time of first cancer diagnosis.

We report here a case of a woman harboring a de novo TP53 mutation, diagnosed with a chest wall sarcoma, who subsequently developed lung and breast cancer, one of them in the radiation fields, and later contralateral ductal carcinoma in situ (DCIS) and jaw osteosarcoma. 
Table 12009 Chompret criteria for germline TP53 mutation screening

I. Proband with tumor belonging to LFS tumor spectrum (e.g., soft tissue sarcoma, osteosarcoma, brain tumor, premenopausal breast cancer, adrenocortical carcinoma, leukemia, lung bronchoalveolar cancer) before age 46 years AND at least one first- or second-degree relative with LFS tumor (except breast cancer if proband has breast cancer) before age 56 years or with multiple tumors; OR

II. Proband with multiple tumors (except multiple breast tumors), two of which belong to LFS tumor spectrum and first of which occurred before age 46 years; OR

III. Patient with adrenocortical carcinoma or choroid plexus tumor, irrespective of family history

LFS Li-Fraumeni syndrome

\section{Report}

A 29-year-old woman with a personal history of chest wall sarcoma and second primary lung adenocarcinoma was referred to the oncogenetic clinic for a suspicion of LFS. Three years earlier, she presented a right chest wall lesion beneath the right breast. Biopsy of the lesion revealed a low-grade spindle cell sarcoma. She was treated with a wide surgical excision, axillary lymph node dissection, and adjuvant radiation to the right chest wall. She received 50 Gy in 25 fractions over 37 days. The radiation field included the outer quadrants of the right breast that received $80 \%$ of the radiation dose (Fig. 1).

Twenty-seven months later, a follow-up thoracic and abdominal CT-scan revealed a pulmonary nodule in the superior segment of the left inferior lobe (Fig. 1). The patient underwent a diagnostic wedge resection of the pulmonary nodule, and pathology revealed a 4-mm bronchioloalveolar carcinoma. Of note, the patient had never smoked.

Family history (Fig. 2) disclosed a maternal aunt with a choledochal cancer at age 52 and a sister of her grandmother affected with colon cancer at age 79 . The classical diagnostic criteria of a LFS were not fulfilled, but the occurrence of a sarcoma and lung bronchioalveolar cancer before age 46 years met the updated Chompret criteria, prompting molecular genetic screening for a TP53 germline mutation. After obtaining the patient's written informed consent, a peripheral blood sample was taken to perform analysis of the TP53 gene from genomic DNA. Following PCR amplification and bidirectional sequencing of all coding exons (including intron/exon junctions) of the TP53 gene (Ensembl-ID: ENSG00000141510), a nonsense c.637C $>\mathrm{T}$ (p.Arg213X) mutation in exon 6 was identified. Sequencing of exon 6 in her parents and her brother showed no such variant, indicative of a de novo mutation in the patient.

Thirty-nine months after the initial sarcoma diagnosis and at the same time of the molecular genetic confirmation
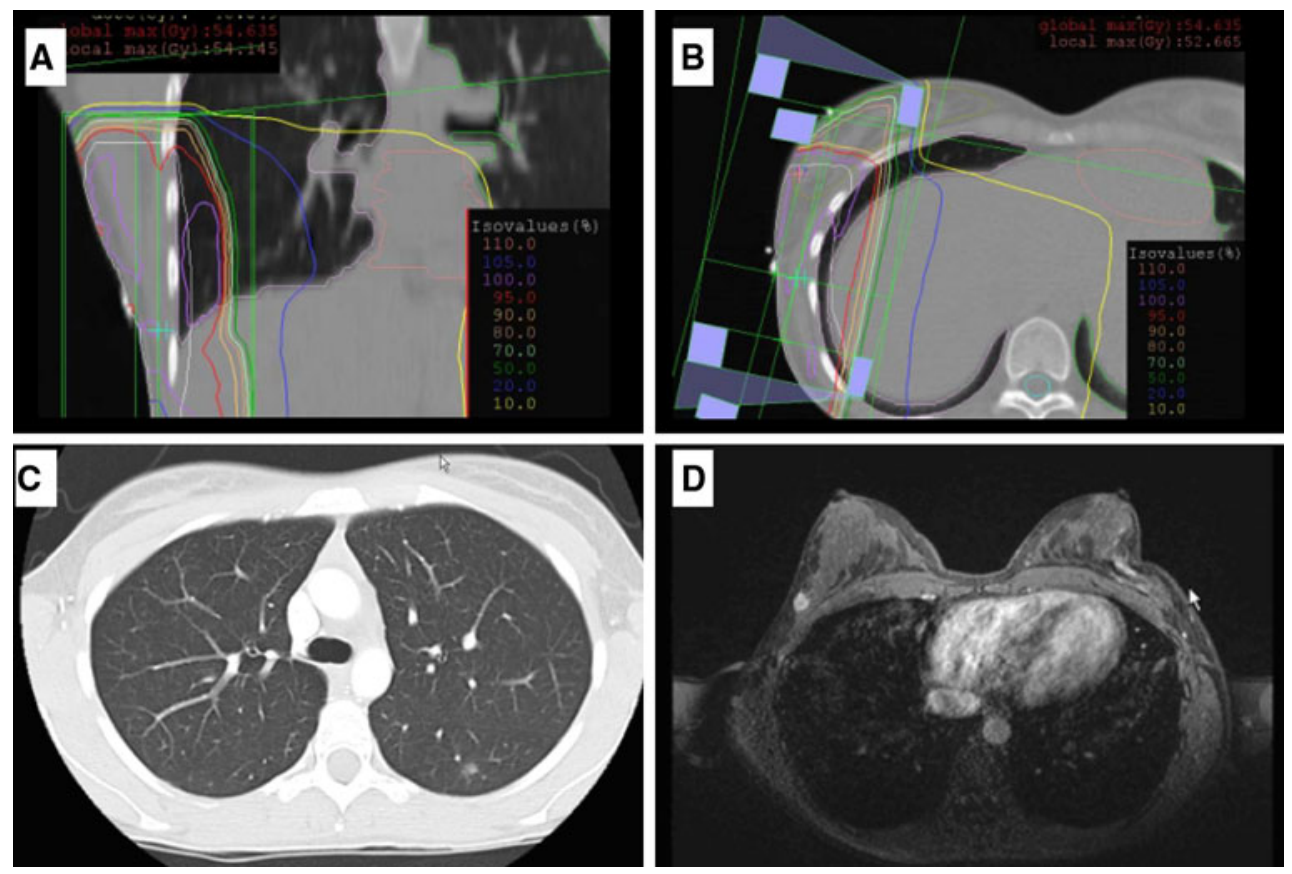

Fig. 1 a Isodose at level of the subsequent lung cancer. b Isodose at level of the subsequent breast cancer. c Contrast enhanced axial chest $\mathrm{CT}$ image showing a pulmonary nodule in the superior region of the

left inferior lobe. d Contrast enhanced (Gadolinium) axial T1weighted MRI showing the tumor in the upper-outer quadrant of the right breast 


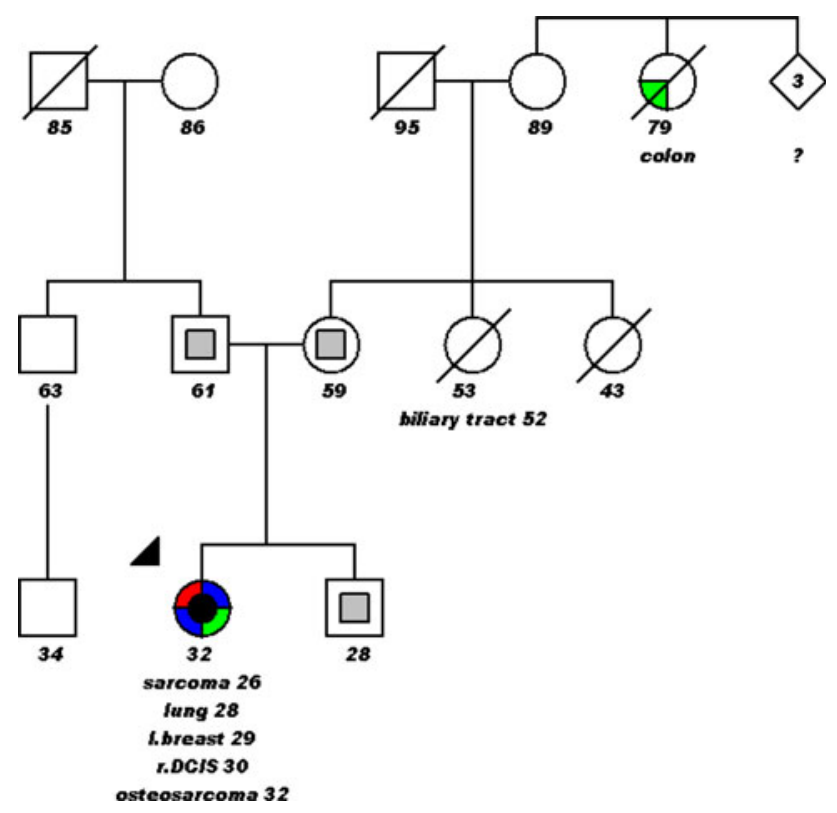

Fig. 2 Pedigree of the p.Arg213X TP53 family: The numbers indicate the current age of the patient and the age at cancer diagnosis, the gray squares indicate the wild-type status, the black circle indicates the mutated status; DCIS ductal carcinoma in situ

of the LFS, the patient presented an upper-outer quadrant lump of her right breast on clinical examination (Fig. 1). Breast magnetic resonance imaging showed a 2-cm Gadolinium-enhanced lesion, and a biopsy confirmed a ductal carcinoma of the breast. Mastectomy of the right breast with sentinel lymph node biopsy was performed. The pathology disclosed a $1.8 \mathrm{~cm}$ in size, poorly differentiated infiltrating ductal carcinoma, with a negative staining for estrogen and progesterone receptors, but a positive staining for the epidermal growth factor receptor 2 . The staging work-up (chest and abdomen CT-scan, bone scan, and liver MRI) was negative. A combined adjuvant treatment with docetaxel, carboplatin, and trastuzumab was initiated. However, the patient refused to continue her treatment after completion of two cycles.

One year later, during the follow-up evaluation, breast MRI showed a 10-mm contrast enhancement in the upperouter quadrant of the left breast. The patient refused a biopsy and requested a mastectomy, which was performed with sentinel nodes biopsy. The pathological report confirmed a 35-mm large DCIS. Sentinel nodes was negative. No additional treatment was proposed. Eighteen months later, jaw pain led to the diagnosis of an osteoblastic bone lesion. A PET-scan (positron emission tomography) did not reveal metastases but strengthen the suspicion of a new primary cancer. Histological analysis of the lesion disclosed an intermediate grade 2 differentiated osteosarcoma. The patient began neoadjuvant chemotherapy. She is now 32 years old.

\section{Discussion}

Using the less stringent Chompret criteria, we have identified a patient harboring a TP53 de novo mutation. In the initial French cohort, a TP53 mutation was identified in only $17 \%$ of the families, using the first Chompret criteria [5]. In contrast, in a recent Spanish cohort, $95 \%$ of patients (71/75) with a TP53 mutation met the new Chompret criteria [6]. Clinical utility of the new criteria has been confirmed by many authors who also reported TP53 mutations in young patients with malignancies typical for LFS, but without a pathognomonic family history fulfilling the LFS criteria [7-9]. For example, in a study of 14 cases of childhood adrenocortical tumors, most germline TP53 mutations carriers did not have a family history fulfilling the classic LFS criteria, leading to the hypothesis of a de novo mutation or a low penetrance phenotype [10]. Our patient is another perfect example where younger patients ( $<46$ years of age) afflicted with multiple primary cancers should be strongly considered for TP53 genetic testing even without a positive family history.

Given the very aggressive phenotype observed in our patient, it is unclear if the p.Arg213X TP53 mutation could be responsible for that particular phenotype. The p.Arg213X TP53 mutation is a non-sense mutation located in exon 6 and has been reported in 287 tumors. Most of the reported somatic and germline TP53 mutations are missense mutations; only $6 \%$ are represented by non-sense mutations. The translated $\mathrm{p} 53$ protein, if not subjected to non-sense-mediated decay, is truncated and has lost most of the DNA-binding domains that are located downstream of amino acid 213. In the IARC TP53 mutations database (http://www-p53.iarc.fr/p53main.html database version R14, November 2009) [11], the p.Arg213X mutation has been reported in 6 families [3, 9, 10, 12-17]. Five of the six articles report clinical and family data in sufficient details and are summarized in Table 2. In one report, the exact relative degree is not mentioned [3]. Finally, in all reported families, genetic testing of relatives is not reported.

Trahair et al. recently reported a female patient who had DCIS at age 30 and 34, low-grade astrocytoma at age 36, and spindle cell sarcoma at age 36 [17]. This case report shares many similarities with ours. These two patients are both female, young at first cancer diagnosis (26 and 30 years, respectively), and both had several primary tumors. The case reported by Trahair is a not a de novo mutation, since many family members presented typical LFS cancers.

The usual phenotype-genotype correlation studies have focused on TP53 mutation presence, location, or type of mutation. An IARC database study of families fulfilling the LFS criteria demonstrates that age at breast cancer diagnosis is younger if a TP53 mutation is present. Brain 
Table 2 Cases with a p.Arg213X mutation as reported in the IARC TP53 mutations database

\begin{tabular}{|c|c|c|}
\hline Reference & $\begin{array}{l}\text { Type of cancer (index case) } \\
\text { (age at diagnosis (years)) }\end{array}$ & Family history (cancer type (relative age)) \\
\hline Frebourg [15] & Breast (27) & Colon (N 9) \\
\hline Reifenberger [16] & Cerebral PNET $(<1)$ & $\begin{array}{l}\text { Cerebral PNET (S 5), ovary (M ?), brain (U 14, U 30), } \\
\text { other (colon, leukemia) }\end{array}$ \\
\hline Varley [10] & Adrenocortical $(<2)$ & Brain (GM 42) \\
\hline Vahteristo [16] & Breast (28) & Sarcoma (64), melanoma (67), lung $(75)^{\mathrm{a}}$ \\
\hline Wong [9] & Colon (9) & Gastric (M 29), sarcoma (GFm 17), breast (Am 27) \\
\hline Trahair [17] & Rhabdomyosarcoma (2) & $\begin{array}{l}\text { Breast and other cancers }{ }^{\mathrm{b}} \text { (M 30, 34), fibrosarcoma } \\
\quad(\mathrm{GFm} 43) \text {, ACC (GCm 8), esophageal (GUm 40), liver (GGFm 20) }\end{array}$ \\
\hline Our case & $\begin{array}{l}\text { Sarcoma (26) } \\
\text { Lung (28) } \\
\text { Breast (29) } \\
\text { Contralateral DCIS (30) } \\
\text { Osteosarcoma (32) }\end{array}$ & \\
\hline
\end{tabular}

tumors are associated with missense TP53 mutations located in the DNA-binding loop that are in contact with the minor groove of DNA; adrenal gland carcinomas with missense mutations located in the loops opposing the protein-DNA contact surface and null phenotype (absence of the protein or loss of function) with earlier onset brain tumors [18]. The most significant defect is loss of function because large deletions encompassing the whole TP53 gene have been found in LFS families with aggressive features [19]. The p.Arg213X TP53 mutation causes the lost of most of the DNA-binding domains that are located downstream of amino acid 213, which could explain the severe phenotype of our case.

Besides TP53 mutations, other genes can act as genetic modifiers. Many other genetic modifiers or other mechanism, not yet available for clinical practice, have been recently identified in LFS families. Polymorphic genetic variants in the p53 stress response pathway could determine an individual's susceptibility to cancer. In the p53 pathway, the MDM2 gene encodes an important negative regulator of p53. A single nucleotide polymorphism in the promoter region of MDM2 (SNP309) leads to a functional attenuation of $\mathrm{p} 53$. In 88 LFS patients harboring a pathogenic TP53 mutation, presence of SNP308 was associated with an earlier tumor onset [20].

DNA rearrangements, such as DNA copy number variation (CNVs), can also predispose cancer development when they encompass, overlap, or disrupt dosage-sensitive genes. TP53, as guardian of the genome, is involved in the very processes known to give rise to $\mathrm{CNVs}$, such as suppression of homologous recombination [21]. Genomic
CNVs analysis in a LFS cohort using high-density oligonucleotide arrays has shown that TP53 mutation carriers displayed a significant increase in CNVs than in TP53 wild-type LFS patients [22].

Among the factors described above, the loss of the DNA-binding domains located downstream of amino acid 213 explains the high number of primary cancers in our patient. To the best of our knowledge, no specific TP53 mutation or modifying genes have explained this "multiple cancers" phenotype. We are aware of only one case report which showed the existence of a double pathogenic mutation of TP53 and BRCA2 [23]. The patient was identified through systematic BRCA1, BRCA2, TP53, CDKN2A germline mutation screening of 82 patients diagnosed with breast cancer and melanoma. A coexisting TP53 mutation and BRCA2 germline mutation was identified. This patient had developed 6 different primary cancers by age 70 .

Finally, we have to strongly consider the potential deleterious influence of the radiotherapy in the rapid development of second primary cancers. High sensitivity to radiation-induced cancers has been reported in vitro [24] and in many TP53 mutation carriers series [25, 26]. In the largest series of $200 \mathrm{Li}-$ Fraumeni syndrome family members diagnosed with cancer, 30 had multiple primary cancers and 8 cases occurred in radiation fields at 3 to 22 years after the treatment [27]. TP53 is involved in various cellular processes such as the regulation of DNA repair and programmed cell death. Our patient presented a lung cancer close to the radiation fields 27 months after radiotherapy, a right breast cancer in the irradiated field 39 months 
after radiotherapy, as well as a left DCIS also close to the radiation fields 53 months after radiotherapy. This exposure to radiation therapy probably explains the short time elapsed between the four primary cancers in our patient. The jaw osteosarcoma, the fifth primary cancer, is the only one to be located outside of the chest and occurred 6 years after the chest sarcoma. This latter time interval corresponds better to the usual occurrence time of a second primary cancer in TP53 families [18].

In summary, this case report illustrates the difficulties in making a definitive diagnosis of LFS in patients lacking a positive family history and also the dangers of treating their primary tumors with radiotherapy when no proper genetic diagnosis has been made. In a near future, availability of high throughput technologies will allow more rapid genetic testing. Thus, patients at risk could be diagnosed earlier as carrier of detrimental gene mutations.

Acknowledgments The authors thank Mrs Lyse Cachat and Dr. François Cachat for their help in editing the manuscript and their thoughtful comments.

\section{References}

1. Li FP, Fraumeni JF Jr, Mulvihill JJ, Blattner WA, Dreyfus MG, Tucker MA, Miller RW (1988) A cancer family syndrome in twenty-four kindreds. Cancer Res 48:5358-5362

2. Tinat J, Bougeard G, Baert-Desurmont S, Vasseur S, Martin C, Bouvignies E, Caron O, Bressac-de PB, Berthet P, Dugast C, Bonaiti-Pellie C, Stoppa-Lyonnet D, Frebourg T (2009) 2009 Version of the chompret criteria for Li Fraumeni syndrome. J Clin Oncol 27:e108-e109

3. Vahteristo P, Tamminen A, Karvinen P, Eerola H, Eklund C, Aaltonen LA, Blomqvist C, Aittomaki K, Nevanlinna H (2001) p53, CHK2, and CHK1 genes in Finnish families with Li-Fraumeni syndrome: further evidence of CHK2 in inherited cancer predisposition. Cancer Res 61:5718-5722

4. Varley JM, Evans DG, Birch JM (1997) Li-Fraumeni syndrome-a molecular and clinical review. Br J Cancer 76:1-14

5. Chompret A, Abel A, Stoppa-Lyonnet D, Brugieres L, Pages S, Feunteun J, Bonaiti-Pellie C (2001) Sensitivity and predictive value of criteria for p53 germline mutation screening. J Med Genet 38:43-47

6. Gonzalez KD, Noltner KA, Buzin CH, Gu D, Wen-Fong CY, Nguyen VQ, Han JH, Lowstuter K, Longmate J, Sommer SS, Weitzel JN (2009) Beyond Li Fraumeni Syndrome: clinical characteristics of families with p53 germline mutations. J Clin Oncol 27:1250-1256

7. Salmon A, Amikam D, Sodha N, Davidson S, Basel-Vanagaite L, Eeles RA, Abeliovich D, Peretz T (2007) Rapid development of post-radiotherapy sarcoma and breast cancer in a patient with a novel germline 'de-novo' TP53 mutation. Clin Oncol (R Coll Radiol) 19:490-493

8. Bendig I, Mohr N, Kramer F, Weber BH (2004) Identification of novel TP53 mutations in familial and sporadic cancer cases of German and Swiss origin. Cancer Genet Cytogenet 154:22-26

9. Wong P, Verselis SJ, Garber JE, Schneider K, DiGianni L, Stockwell DH, Li FP, Syngal S (2006) Prevalence of early onset colorectal cancer in 397 patients with classic Li-Fraumeni syndrome. Gastroenterology 130:73-79
10. Varley JM, McGown G, Thorncroft M, James LA, Margison GP, Forster G, Evans DG, Harris M, Kelsey AM, Birch JM (1999) Are there low-penetrance TP53 Alleles? evidence from childhood adrenocortical tumors. Am J Hum Genet 65:995-1006

11. Petitjean A, Mathe E, Kato S, Ishioka C, Tavtigian SV, Hainaut P, Olivier M (2007) Impact of mutant p53 functional properties on TP53 mutation patterns and tumor phenotype: lessons from recent developments in the IARC TP53 database. Hum Mutat 28:622-629

12. Olivier M, Eeles R, Hollstein M, Khan MA, Harris CC, Hainaut $P$ (2002) The IARC TP53 database: new online mutation analysis and recommendations to users. Hum Mutat 19:607-614

13. Birch JM, Alston RD, McNally RJ, Evans DG, Kelsey AM, Harris M, Eden OB, Varley JM (2001) Relative frequency and morphology of cancers in carriers of germline TP53 mutations. Oncogene 20:4621-4628

14. Horio Y, Suzuki H, Ueda R, Koshikawa T, Sugiura T, Ariyoshi Y, Shimokata K, Takahashi T, Takahashi T (1994) Predominantly tumor-limited expression of a mutant allele in a Japanese family carrying a germline p53 mutation. Oncogene 9:1231-1235

15. Frebourg T, Barbier N, Yan YX, Garber JE, Dreyfus M, Fraumeni J Jr, Li FP, Friend SH (1995) Germ-line p53 mutations in 15 families with Li-Fraumeni syndrome. Am J Hum Genet 56:608-615

16. Reifenberger J, Janssen G, Weber RG, Bostrom J, Engelbrecht V, Lichter P, Borchard F, Gobel U, Lenard HG, Reifenberger G (1998) Primitive neuroectodermal tumors of the cerebral hemispheres in two siblings with TP53 germline mutation. J Neuropathol Exp Neurol 57:179-187

17. Trahair T, Andrews L, Cohn RJ (2007) Recognition of Li Fraumeni syndrome at diagnosis of a locally advanced extremity rhabdomyosarcoma. Pediatr Blood Cancer 48:345-348

18. Olivier M, Goldgar DE, Sodha N, Ohgaki H, Kleihues P, Hainaut P, Eeles RA (2003) Li-Fraumeni and related syndromes: correlation between tumor type, family structure, and TP53 genotype. Cancer Res 63:6643-6650

19. Bougeard G, Brugieres L, Chompret A, Gesta P, Charbonnier F, Valent A, Martin C, Raux G, Feunteun J, Bressac-de PB, Frebourg T (2003) Screening for TP53 rearrangements in families with the Li-Fraumeni syndrome reveals a complete deletion of the TP53 gene. Oncogene 22:840-846

20. Bond GL, Hu W, Bond EE, Robins H, Lutzker SG, Arva NC, Bargonetti J, Bartel F, Taubert H, Wuerl P, Onel K, Yip L, Hwang SJ, Strong LC, Lozano G, Levine AJ (2004) A single nucleotide polymorphism in the MDM2 promoter attenuates the p53 tumor suppressor pathway and accelerates tumor formation in humans. Cell 119:591-602

21. Lane DP (1992) Cancer. p53, guardian of the genome. Nature 358:15-16

22. Shlien A, Tabori U, Marshall CR, Pienkowska M, Feuk L, Novokmet A, Nanda S, Druker H, Scherer SW, Malkin D (2008) Excessive genomic DNA copy number variation in the Li-Fraumeni cancer predisposition syndrome. Proc Natl Acad Sci USA 105:11264-11269

23. Monnerat C, Chompret A, Kannengiesser C, Avril MF, Janin N, Spatz A, Guinebretiere JM, Marian C, Barrois M, Boitier F, Lenoir GM, Bressac-de PB (2007) BRCA1, BRCA2, TP53, and CDKN2A germline mutations in patients with breast cancer and cutaneous melanoma. Fam Cancer 6:453-461

24. Boyle JM, Spreadborough AR, Greaves MJ, Birch JM, Varley JM, Scott D (2002) Delayed chromosome changes in gammairradiated normal and Li-Fraumeni fibroblasts. Radiat Res 157:158-165

25. Limacher JM, Frebourg T, Natarajan-Ame S, Bergerat JP (2001) Two metachronous tumors in the radiotherapy fields of a patient with Li-Fraumeni syndrome. Int J Cancer 96:238-242 
26. Nutting C, Camplejohn RS, Gilchrist R, Tait D, Blake P, Knee G, Yao WQ, Ross G, Fisher C, Eeles R (2000) A patient with 17 primary tumours and a germ line mutation in TP53: tumour induction by adjuvant therapy? Clin Oncol (R Coll Radiol) $12: 300-304$
27. Hisada M, Garber JE, Fung CY, Fraumeni JF Jr, Li FP (1998) Multiple primary cancers in families with Li-Fraumeni syndrome. J Natl Cancer Inst 90:606-611 